\title{
Expression of Claudin-7 Molecule in Canine Perianal GlandTumours
}

\author{
Csaba Jakab ${ }^{1}$, Miklós Rusvai ${ }^{1}$, Péter Gálfi ${ }^{2}$, Janina Kulka ${ }^{3}$ \\ ${ }^{1}$ Szent István University, Faculty of Veterinary Science, \\ Department of Pathology and Forensic Veterinary Medicine, Budapest, Hungary \\ ${ }^{2}$ Szent István University, Faculty of Veterinary Science, Department of Pharmacology and Toxicology, \\ Budapest, Hungary \\ ${ }^{3} 2^{\text {nd }}$ Department of Pathology, Semmelweis University, Budapest, Hungary
}

Received: January 2, 2008

Accepted: September 8, 2009

\begin{abstract}
The present study evaluated the expression of claudin-7 in 10 intact perianal gland and 67 hyperplastic and neoplastic lesions of the canine perianal (hepatoid) gland. The results have shown intense typical membrane expression of claudin-7 in intact perianal glands, hyperplasia, adenoma, differentiated and anaplastic carcinoma of this gland. In intact glands, hyperplasias, adenomas of the hepatoid gland, normal, hyperplastic and neoplastic basal cells never expressed claudin-7 molecule. Epitheliomas of the hepatoid gland were negative for claudin-7 molecule. Intense membrane-bound claudin-7 immunoreactivity was found in well-differentiated carcinomas, in addition claudin-7 overexpression in poorly differentiated carcinomas of the canine hepatoid gland. Claudin-7 seems to be one of the integral constituents of tight junction structures of intact perianal gland. In addition, claudin-7 seems to be helpful in distinguishing well-differentiated carcinomas and poorly differentiated carcinomas from epitheliomas of the gland; and in distinguishing well-differentiated carcinomas from adenoma of the perianal gland.
\end{abstract}

Canine, hepatoid gland tumours, claudin-7, immunohistochemistry

Perianal or hepatoid glands are modified sebaceous glands in canines located mainly in perianal skin but they also occur in the skin lateral to the prepuce, in the dorsal lumbosacral region, along the ventral midline area, and circumferentially around the proximal third of the tail. The cells of the lobules of these glands can be divided into two groups: mature hepatoid cells and peripheral basal reserve cells (Isitior and Weinman 1979). The function of the hepatoid glands is unknown. The perianal glands have been of interest to veterinarians because they frequently give rise to tumours. The proliferative and neoplastic lesions of the hepatoid gland include hyperplasia, adenoma, epithelioma, well differentiated and poorly differentiated carcinoma. The hepatoid gland hyperplasia and adenoma are common lesions in canines and account for $8 \%$ to $18 \%$ of all canine skin tumours (Goldschmidt and Hendrick 2000). The hepatoid gland epitheliomas are of low-grade malignancy. These neoplasms are characterized by the majority of cells being reserve cells, with fewer hepatoid cells (Goldschmidt and Shofer 1992). Well-differentiated hepatoid gland carcinomas have a similar histological architecture and morphology to adenomas, but infiltrative growth is present at the tumour margins. Small foci of well-differentiated carcinoma may occur within adenomas, which may represent carcinoma in situ. Poorly differentiated carcinomas of the perianal gland are invasive masses comprising trabeculae and cords of large, polygonal cells (Ihrke et al. 2006).

Claudins are a relatively large family of $17-27 \mathrm{kDa}$ integral membrane tight junction tetraspanin proteins that are classified on the basis of the size of the molecules that pass through the paracellular spaces between epithelial and endothelial cells. Tight junctions are the most apical cell-cell contacts and are important for barrier function in epithelial and endothelial cells (Tsukita and Furuse 2002; Tsukita et al. 2001). The claudin family consists of at least 24 members (Morita et al. 1999). Claudins encode proteins with four

Address for correspondence:

Csaba Jakab

Szent István University, Faculty of Veterinary Science

Department of Pathology and Forensic Veterinary Medicine

1078 István utca 2., Budapest, Hungary
Phone: +36-1-478-4181

Fax: $+36-1-478-4284$

E-mail: Jakab.Csaba@aotk.szie.hu

http://www.vfu.cz/acta-vet/actavet.htm 
transmembrane domains, and their $\mathrm{N}$ - and C-terminal ends are located in the cytoplasm. Claudin molecules interact with each other through homo- and heterophilic interactions. In addition, the C-terminal domain of claudins also serves as a binding site of PDZ domain proteins that are potentially involved in signalling (Hamazaki et al. 2002).

The aim of the present study was to characterise the expression pattern of claudin-7 tight junction protein in canine intact hepatoid glands and in proliferative lesions of this gland including nodular hyperplasia, adenoma, epithelioma, well-differentiated carcinoma and poorly differentiated carcinoma.

\section{Materials and Methods}

Tissue Samples

Biopsy samples of canine hepatoid gland proliferative lesions $(n=77)$ were submitted for diagnosis to the Szent István University, Faculty of Veterinary Science, Department of Pathology and Forensic Veterinary Medicine. The samples were fixed in $8 \%$ neutral buffered formalin for $24 \mathrm{~h}$ at room temperature, dehydrated in a series of ethanol and xylene baths and embedded in paraffin wax. Sections (3-4 $\mu \mathrm{m})$ were stained with haematoxylin and eosin $(\mathrm{HE})$. We investigated intact hepatoid glands $(\mathrm{n}=10)$, hepatoid gland nodular hyperplasias $(\mathrm{n}=10)$, adenomas $(n=12)$, epitheliomas $(n=15)$, well differentiated hepatoid gland carcinomas $(n=15)$, and poorly differentiated hepatoid gland carcinomas $(n=15)$ from the perianal region. Histological classification of the hepatoid gland proliferative lesions was based on the book Skin Diseases of the Dog and Cat: Clinical and Histopathologic Diagnosis (Ihrke et al. 2006). Intact hepatoid gland samples were collected from 3 female and 7 male dogs with an average age of 7.3 years (range 5-10 years). The hyperplasia study group comprised 6 females, 4 males with an average age of 9.2 years (range 8-12 years). The adenoma study group comprised 6 females and 6 males with an average age of 8.6 years (range 7-10 years). The hepatoid gland epithelioma samples were collected from 8 female and 7 male dogs with an average age of 9.9 years (range 7-13 years). The well differentiated hepatoid gland carcinoma study group comprised 9 females and 6 males with an average age of 10.7 years (range 8-15 years). The poorly differentiated hepatoid gland carcinoma samples were collected from 11 females and 4 males dogs with an average age of 12.4 years (range 9-16 years).

\section{Immunohistochemistry}

Serial sections (3-4 $\mu \mathrm{m}$ ) were initially de-waxed in xylene and graded ethanol. After treatment with appropriate antigen retrieval (Target Retrieval Solution, DAKO, Glostrup, Denmark, $\mathrm{pH} 6$; microwave - $800 \mathrm{~W}$ - oven for $30 \mathrm{~min}$ ), the sections were incubated with primary antibody against claudin-7 (diluted 1:80, rabbit polyclonal, Zymed Inc., San Francisco, CA, USA) for $60 \mathrm{~min}$ at room temperature. Immunohistochemical labelling was performed using the streptavidin-peroxidase procedure. Antigen-bound primary antibody was detected using standard avidin-biotin immunoperoxidase complex (DAKO, LSAB2 Kit). The chromogen substrate was 3,3'-diaminobenzidine tetrahydrochloride (DAB substrate-chromogen, DAKO). Sections were counterstained with Mayer's haematoxylin.

Negative control was performed by omission of the primary antibody and external positive control were the epithelial cells of the terminal ductulo-lobular unit from normal mammary gland tissue (Jakab et al. 2008a). Internal positive controls were the peritumoral intact and hyperplastic apocrine glands (Plate XII, Fig. 1a-1b) (Jakab et al. 2008b). The peritumoural fibroblasts, endothelial cells, and lipocytes served as internal negative controls since these cells do not express claudin-7 protein.

In each case, two independent observers (CSJ and $\mathrm{JK}$ ) recorded the distribution and intensity of labelling. The percentage of positively labelled cells was determined by counting 100 cells in 10 randomly selected fields per slide $(\times 20$ objective). Numerical scores were assigned to the lesions on the basis of these counts: $0(0-5 \%$ positively labelled cells), 1 (5-20\% positively labelled cells), 2 (20-40\% positively labelled cells), 3 (40-60\% positively labelled cells), 4 (60-80\% positively labelled cells) and 5 (80-100\% positively labelled cells).

\section{Results}

The expression of claudin-7 molecule within the different categories of proliferative lesions of hepatoid gland is summarized in Table 1. Claudin-7 was detected as intense lateral membrane labelling of epithelial cells (mature hepatoid cells) in normal hepatoid glands (scoring: 5 [range $=5-5$ ]; 90-100\% cell positivity) (Plate XII, Fig. 2), perianal gland hyperplasias (scoring: 4,9 [range $=4-5]$; 70-100\% cell positivity) (Fig. 3) and adenomas (scoring: 4,9 [range $=4-5$ ]; 70-100\% cell positivity) (Fig. 4). In the intact hepatoid gland, nodular hyperplasia and adenoma, the basal cells never showed positivity for claudin-7 molecule. The epitheliomas of the canine hepatoid gland were negative for claudin-7 (Fig. 5). Intense lateral membrane immunoreactivity was found in the well- 
Table 1. Summary of expression of the claudin-7 protein in canine hepatoid gland lesions

\begin{tabular}{|l|c|c|c|c|c|c|}
\hline $\begin{array}{l}\text { Lesion type of } \\
\text { hepatoid gland }\end{array}$ & Healthy gland & Hyperplasia & Adenoma & Epithelioma & $\begin{array}{c}\text { Well differentiated } \\
\text { carcinoma }\end{array}$ & $\begin{array}{c}\text { Poorly differentiated } \\
\text { carcinoma }\end{array}$ \\
\hline Age & $7.3(5-10)$ & $9.2(8-12)$ & $8.6(7-10)$ & $9.93(7-13)$ & $10.73(8-15)$ & $12.4(9-16)$ \\
\hline Sex & $7 \mathrm{M} / 3 \mathrm{~F}$ & $4 \mathrm{M} / 6 \mathrm{~F}$ & $6 \mathrm{M} / 6 \mathrm{~F}$ & $7 \mathrm{M} / 8 \mathrm{~F}$ & $6 \mathrm{M} / 9 \mathrm{~F}$ & $4 \mathrm{M} / 11 \mathrm{~F}$ \\
\hline Number of cases & 10 & 10 & 12 & 15 & 15 & 15 \\
\hline Claudin-7 & $5(5-5)$ & $4.9(4-5)$ & $4.9(4-5)$ & $0(0-0)$ & $4.2(4-5)$ & $5(5-5)$ \\
\hline
\end{tabular}

differentiated carcinomas (scoring: 4.2 [range $=4-5] ; 60-90 \%$ tumour cell positivity). In the well-differentiated carcinomas, $10-30 \%$ tumour cells showed a fine non-granular cytoplasmic positivity for claudin-7 with or without typical membrane expression of claudin-7 protein (Plate XIII, Figs 6-7). Poorly differentiated hepatoid gland carcinomas showed an overexpression for claudin-7 (scoring: 5 [range $=5-5$ ]; 80-100\% tumour cell positivity). In poorly differentiated carcinomas, 10-40\% neoplastic cells showed cytoplasmic positivity for claudin-7 with typical membrane expression for claudin-7 protein (Plate XIII, Figs 8-9). Epithelial cells of normal and hyperplastic apocrine glands showed intense membrane positivity for claudin-7 and we used these as internal positive controls. In the apocrine glands, claudin-7 immunoreactivity was stronger than in intact hepatoid glands, hyperplasias and adenomas, but it was similarly strong in differentiated and poorly differentiated carcinomas.

\section{Discussion}

Adhesion between neighbouring epithelial cells is a crucial and tightly controlled process. In epithelial cells, specialized structures such as tight junctions and adherent junctions are responsible for establishment of contacts between neighbouring cells. Claudins including claudin-7 are key components of epithelial and endothelial tight junctions, which act as a barrier to the paracellular flux of water, solutes, and transmigration of other cells. Claudins are exclusively responsible for the formation of tight junction strands and the second function of these proteins is preservation of cell polarity in the epithelial and endothelial barriers. These transmembrane proteins are connected to the actin cytoskeleton via a network of proteins such as zonula occludens-1 (ZO-1) (Furuse et al. 1999; Tsukita et al. 2002; Van Itallie et al. 2001). These tight junction proteins have been proposed to play important roles in different biological processes including embryogenesis, development, tissue remodelling, and oncogenesis. The preservation of cell polarity and paracellular flux by many claudin molecules suggests that these proteins contribute to tumour suppressive functions in epithelial neoplasia (Karen et al. 2005). The barrier function of the tight junctions and claudins regulates the passage of ions, water, and different macromolecules, growth factors through paracellular space. The tight junctions and claudins between epithelial cells form a polarized barrier between luminal and serosal compartments and segregate luminal growth factor from their basal-lateral receptors. This property may promote cancer formation in pre-neoplastic, pre-malignant tissues in which the tight junctions and claudins have become chronically leaky to growth factors (Mullin 1997; 2004). The loss of claudins and other tight junction proteins has been suggested to underlie the loss of cell adhesion and to be an important step in the development of tumour invasion and metastasis (Karen et al. 2005). Claudins have been shown to modify tumour invasion by the regulation of matrix metalloproteinases (MMPs). Several members of the claudinfamily such as claudin-2 and claudin-5 are able to activate membrane-type-1-MMPmediated pro-MMP-2 processing (Miyamori et al. 2001).

We have reported previously that claudin-7 is one of the integral constituents of tight junction structures of normal canine mammary gland (Jakab et al. 2008a), canine 
primer (Jakab et al. 2008c), and secondary epithelial mammary gland tumours (Jakab et al. 2009). In the present study we examined the expression of claudin-7 in 10 normal and 67 proliferative, neoplastic lesions of the canine hepatoid gland including hepatoid gland nodular hyperplasias $(n=10)$, adenomas $(n=12)$, epitheliomas $(n=15)$, well differentiated hepatoid gland carcinomas $(n=15)$, and poorly differentiated hepatoid gland carcinomas $(n=15)$ from the perianal region. To our knowledge, this is the first study that has examined claudin-7 expression by intact and hepatoid gland tumours. In this study we have detected an intense membrane-expression of claudin-7 tight junction molecule in intact hepatoid glands, hyperplasias, and adenomas. Intact perianal gland and hyperplastic basal cells never showed positivity for claudin-7 molecule in these lesions. Epitheliomas of the canine hepatoid gland never expressed claudin-7 protein but intense lateral membrane immunoreactivity was found in well-differentiated carcinomas. Poorly differentiated hepatoid gland carcinomas showed overexpression for claudin-7 protein.

Claudin-7 seems to be one of the integral constituents of tight junction structures of intact perianal gland. Claudin- 7 and claudin- 8 are expressed normally in the distal nephron epithelium of kidneys (Li et al. 2004). This tight junction molecule is a novel immunohistochemical marker for renal tumour classification. The distal nephron marker claudin-7 overexpressed in human chromophobe renal cell carcinoma (RRC) versus oncocytoma and other tumour subtypes. Claudin-7 protein is a candidate expression marker for distinguishing chromophobe RRC from other renal tumour subtypes, including the morphologically similar oncocytoma (Hornsby et al. 2007). In our study we have found that claudin-7 molecule was never expressed in epitheliomas. Intense lateral membrane immunoreactivity was found in well-differentiated carcinomas, and anaplastic, poorly differentiated hepatoid gland carcinomas showed an overexpression for claudin-7 protein. Claudin-7 seems to be helpful in distinguishing well-differentiated carcinomas and poorly differentiated carcinomas from epitheliomas of the canine hepatoid gland. In addition, claudin-7 can help distinguish poorly differentiated carcinomas from well-differentiated carcinomas arising from the canine hepatoid gland. Well-differentiated hepatoid gland carcinomas have a similar histological architecture and morphology to adenomas, but infiltrative growth is present at the tumour margins (Ihrke et al. 2006). In this present study intense lateral membrane immunoreactivity was found in adenomas (scoring: 4.9; $70-100 \%$ cell positivity) and in well-differentiated carcinomas (scoring: $4.2 ; 60-90 \%$ cell positivity). In addition, in well-differentiated carcinomas, 10-30\% tumour cells showed a cytoplasmic positivity for claudin-7 in contrast to adenoma. In our opinion, claudin-7 can help distinguish well-differentiated carcinomas from adenomas arising from the canine hepatoid gland.

Claudin-7 plays an important role in human immunodeficiency virus (HIV) infection of CD4(-) cells. This protein can serve as a receptor for HIV-1 infection of CD4(-) cells or as a ligand on the viral envelope (Zheng et al. 2005).

One human study described claudin-7 overexpressed in gastric dysplasia and adenocarcinoma but not in the surrounding non-neoplastic epithelial cells. These results suggest that claudin-7 expression is an early event in gastric tumourigenesis that is maintained throughout tumour progression (Johnson et al. 2005). This tight junction protein overexpressed in human squamous cell carcinomas of the uterine cervix (Sobel et al. 2005) as well as in the adenocarcinoma of the esophagus (Montgomery et al. 2006). In contrast, it is underexpressed in the ductal carcinoma of the breast (Kominsky et al. 2003). In our study we described the claudin-7 protein overexpressed in poorly differentiated hepatoid gland carcinomas. The precise mechanism behind the increased expression of claudin-7 and its biological role in canine hepatoid gland carcinogenesis will be the subject of future studies. Overexpression of claudin molecules in cancer may dysregulate cell 
signalling, polarity, or adhesion via interactions with other proteins (Miwa et al. 2000). Underexpression of these proteins may reduce cell adhesion as neoplasms progress to an invasive or metastatic phenotype (Usami et al. 2006).

In our study we found that in well-differentiated carcinomas, 10-30\% tumour cells showed a fine cytoplasmic positivity for claudin-7 with or without typical membrane expression of claudin-7 protein and in poorly differentiated carcinomas of the hepatoid gland, 10-40\% neoplastic cells showed a cytoplasmic positivity for claudin-7 with typical membrane expression of claudin-7 protein. Non-junctional claudin-1 has been noted in rat epididymis (Gregory et al. 2001), porcine brain capillary endothelial cells (Ishizaki et al. 2003) and in a selected subline of MDCK cells (Amasheh et al. 2002). However, its function outside of tight junction in these cells is not known. In some, non-junctional claudin-1 has been correlated with tumorigenesis and/or metastasis (Miwa et al. 2000). The loss of membrane claudin expression and its re-localization to the nucleus and cytoplasm has been previously reported for both human colon (Dhawawn et al. 2005) and breast cancer (Kominsky et al. 2003). Down-regulation of claudin-7 expression has been reported in human breast cancer (Kominsky et al. 2004) and in canine mammary gland cancers (Jakab et al. 2008c). Claudin expression is lost as both the direct result of protein down-regulation as well as phosphorylation by MAP kinase (Fujibe et al. 2004), protein kinase C (Banan et al. 2005), cAMP-dependent protein kinase (D'Souza et al. 2005) and WNK-4 kinase leading to junction disruption and cytoplasmic internalization (Yamauchi et al. 2004). Further functional studies are needed to clarify the biological role of mislocalization of claudin-7, from the cell membrane to the cytoplasm, in carcinomas of the canine hepatoid gland tumour.

In conclusion, the results of the present study have shown intense typical membraneexpression of claudin-7 in canine normal hepatoid gland, hyperplasia, adenoma, welldifferentiated and poorly differentiated carcinoma of this gland. In intact glands, hyperplasias, adenomas of the canine hepatoid gland, intact, hyperplastic and neoplastic basal cells never expressed claudin-7 molecule. Epitheliomas of the canine hepatoid gland were negative for claudin-7 molecule. Intense membrane-bound claudin-7 immunoreactivity was found in well-differentiated carcinomas, in addition claudin-7 overexpression in poorly differentiated carcinomas of the canine hepatoid gland. Claudin-7 seems to be one of the integral constituents of tight junction structures of intact canine hepatoid gland. In addition, claudin-7 seems to be helpful in distinguishing well-differentiated carcinomas and poorly differentiated carcinomas from epitheliomas of the canine hepatoid gland; and it can help distinguish well-differentiated carcinomas from adenomas arising from the canine hepatoid gland. In well-differentiated carcinomas, 10-30\% tumour cells, and in poorly differentiated hepatoid gland carcinomas, 10-40\% neoplastic cells showed cytoplasmic positivity for claudin-7 with or without the typical membrane expression of claudin-7 protein. Further functional studies are needed to clarify the biological role of mislocalization of claudin-7 from the cell membrane to the cytoplasm in the carcinomas of the canine hepatoid gland tumour.

\section{Acknowledgments}

We thank Magdolna Pekár and Renata Pop for their assistance with immunohistochemistry and Edit Oláh for her help in locating the relevant references.

\section{References}

Amasheh S, Meiri N, Gitter AH, Schoneberg T, Mankertz J, Schulzke JD, Fromm M 2002: Claudin-2 expression induces cation-selective channels in tight junctions of epithelial cells. J Cell Sci 115: 4969-4976

Banan A, Zhang LJ, Shaikh M, Fields JZ, Farhadi A, Keshavarzian A 2005: Theta isoform of protein kinase $\mathrm{C}$ alters barrier function in intestinal epithelium through modulation of distinct claudin isotypes: a novel mechanism for regulation of permeability. J Pharmacol Exp Ther 313: 962-982 
Dhawan P, Singh AB, Deane NG, No Y, Shiou SR, Schmidt C, Neff J, Washington MK, Beauchamp RD 2005: Claudin-1 regulates cellular transformation and metastatic behavior in colon cancer. J Clin Inv 115: 1765-1776

D'souza T, Agarwai R, Morin PJ 2005: Phosphorylation of claudin-3 at threonine 192 by cAMP-dependent protein kinase regulates tight junction barrier function in ovarian cancer cells. J Biol Chem 280: 26233-26240

Fujibe M, Chiba H, Kojima T, Soma T, Wada T, Yamashita T, Sawada N 2004: Thr203 of claudin-1, a putative phosphorylation site for MAP kinase, is required to promote the barrier function of tight junctions. Exp Cell Res 295: 36-47

Furuse M, Sasaki H, Tsukita S 1999: Manner of interaction of heterogeneous claudin species within and between tight junction strands. J Cell Biol 147: 891-903

Goldschmidt M, Hendrick M 2000: Tumors of the skin and soft tissue. In: Meuten, D. (Ed.), Tumor in domestic animals, $4^{\text {th }}$ edition, Iowa State Press, pp. 68-70

Goldschmidt M, Shofer F 1992: Skin tumors of the dog and cat. Pergamon Press, Oxford, pp. 66-71

Gregory M, Dufrense J, Hermo L, Cyr DG 2001: Claudin-1 is not restricted to tight junctions in the rat epididymis. Endocrinol 142: 854-863

Hamazaki Y, Itoh M, Sasaki H, Furuse M, Tsukita S 2002: Multi-PDZ domain protein 1 (MUPP1) is concentrated at tight junctions through its possible interaction with claudin-1 and junctional adhesion molecule. J Biol Chem 277: 455-461

Hornsby CD, Cohen C, Amin MB, Picken MM, Lawson D, Yin-Goen Q, Young AN 2007: Claudin-7 immunohistochemistry in renal tumors: a candidate marker for chromophobe renal cell carcinoma identified by gene expression profiling. Arch Pathol Lab Med 131: 1541-1547

Ihrke PJ, Walder EJ, Affolter VK 2006: Skin Diseases of the Dog and Cat: Clinical and Histopathologic Diagnosis. $2^{\text {nd }}$ Edition, Blackwell Publishing, pp. 655-665

Ishizaki T, Chiba H, Kojima T, Fujibe M, Soma T, Miyajima H, Nagasawa K, Wada I, Sawada N 2003: Cyclic AMP induces phosphorylation of claudin-5 immunoprecipitates and expression of claudin-5 gene in bloodbrain-barrier endothelial cells via protein kinase A-dependent and -independent pathways. Experim Cell Res 290: $275-288$

Isistor GN, Weinman DE 1979: Origin and early development of canine circumanal glands. Am J Vet Res 40: 487-492

Jakab Cs, Halász J, Szász AM, Batmunkh E, Kiss A, Schaff Zs, Rusvai M, Gálfi P, Kulka J 2008a: Expression and localisation of claudin-1, $-2,-3,-4,-5,-7$ and -10 proteins in the normal canine mammary gland. Acta Vet Hung 56: 341-352

Jakab Cs, Halász J, Kiss A, Schaff Zs, Rusvai M, Kulka J 2008b: Use of external positive controls in claudinexpression immunohistochemical examination [in Hungarian, with English abstract and figures]. Magy Állatorvosok Lapja 130: 433-438

Jakab Cs, Halász J, Szász AM, Kiss A, Schaff Zs, Rusvai M, Gálfi P, Kulka J 2008c: Expression of claudin-1, -2, $-3,-4,-5$, and -7 proteins in benign and malignant canine mammary gland epithelial tumours. J Comp Pathol 139: $238-245$

Jakab Cs, Szász AM, Kiss A, Schaff Zs, Rusvai M, Szabára Á, Kulka J 2009: Immunohistochemical examination of expression patterns of claudin molecules in metastases of solid carcinoma simplex from canines [in Hungarian, with English abstract and figures]. Magy Állatorvosok Lapja, 131: 33-41.

Johnson AH, Frierson HF, Zaika A, Powell SM, Roche J, Crowe S, Moskaluk CA, El-Rifai W 2005: Expression of tight-junction protein claudin-7 is an early event in gastric tumorigenesis. Am J Pathol 167: 577-584

Karen S, Robert M, Manfred K 2005: Role of claudins in tumorigenesis. Adv Drug Del Rev 57: 919-928

Kominsky SL, Argani P, Korz D, Evron E, Raman V, Garrett E, Rein A, Sauter G, Kallioniemi OP, Sukumar S 2003: Loss of the tight junction protein claudin-7 correlates with histological grade in both ductal carcinoma in situ and invasive ductal carcinoma of the breast. Oncogene 22: 2021-2033

Kominsky SL, Vali M, Korz D, Gabig TG, Weitzman SA, Argani P, Sukumar S 2004: Clostridium perfringens enterotoxin elicits rapid and specific cytolysis of breast carcinoma cells mediated through tight junction proteins claudin 3 and 4. Am J Pathol 164: 1627-1634

Li Wy, Huey CL, Yu As 2004: Expression of claudin-7 and -8 along the mouse nephron. Am J Physiol Renal Physiol 286: 1063-1071

Miwa N, Furuse M, Tsukita S, Niikawa N, Nakamura Y, Furukawa Y 2000. Involvement of claudin-1 in betacatenin/Tcf signaling pathway and its frequent upregulation in human colorectal cancers. Oncol Res 12: 469-476

Miyaori H, Takino T, Kobayashi Y, Tokai H, Itoh Y, Seiki M, Sato H 2001: Claudin promotes activation of promatrix metalloproteinase-2 mediated by membrane-type matrix metalloproteinases. J Biol Chem 276: 2820428211

Montgomery E, Mamelak AJ, Gibson M, Maitra A, Sheikh S, Amr SS, Yang S, Brock M, Forastiere A, Zhang S, Murphy KM, Berg KD 2006: Overexpression of claudin proteins in esophageal adenocarcinoma and its precusor lesions. Appl Immunohistochem Mol Morphol 14: 24-30

Morita K, Furuse M, Fujimoto K, Tsukita S 1999: Claudin multigene family encoding four transmembrane domain protein components of tight junction strands. Proc Natl Acad Sci USA 96: 511-516 
Mullin JM 1997: Potential interplay between luminal growth factors and increased tight junction permeability in epithelial carcinogenesis. J Experim Zool 279: 484-489

Mullin JM 2004: Epithelial barriers, compartmentation, and cancer. Sci STKE 216: 2-4

Sobel G, Paska Cs, Szabó I, KissA, Kádár A, Schaff Zs 2005: Increased expression of claudins in cervical squamous intraepithelial neoplasia and invasive carcinoma. Human Pathol 36: 162-169

Tsukita S, Furuse M 2002: Claudin-based barrier in simple and stratified cellular sheets. Curr Opin Cell Biol 14: 531-536

Tsukita S, Furuse M, Itoh M 2001: Multifunctional strands in tight junctions. Nat Reviews Mol Cell Biol 2: 285-293

Usami Y, Chiba H, Nakayama F, Ueda J, Matsuda Y, Sawada N, Komori T, Ito A, Yokozaki H 2006: Reduced expression of claudin-7 correlates with invasion and metastasis in squamous cell carcinoma of the esophagus. Human Pathol 37:569-577

Van Itallie C, Rahner C, Anderson JM 2001: Regulated expression of claudin-4 decreases paracellular conductance through a selective decrease in sodium permeability. J Clin Investig 50: 1319-1327

Yamauchi K, Rai T, Kobayashi K, Sohara E, Suzuki T, Itoh T, Suda S, Hayama A, Sasaki S, Uchida S 2004: Disease-causing mutant WNK4 increases paracellular chloride permeability and phosphorylates claudins. Proc Natl Acad Sci USA 101: 4690-4694

Zheng J, Xie Y, Campbel R, Song J, Massachi S, Razi M, Chiu R, Berenson J, Yang OO, Chen IS, Pang S 2005 : Involvement of claudin-7 in HIV infection of CD4(-) cells. Retrovirol 2: $79-92$ 

Plate XII

Jakab C. et al.: Expresion ... pp. 127-134

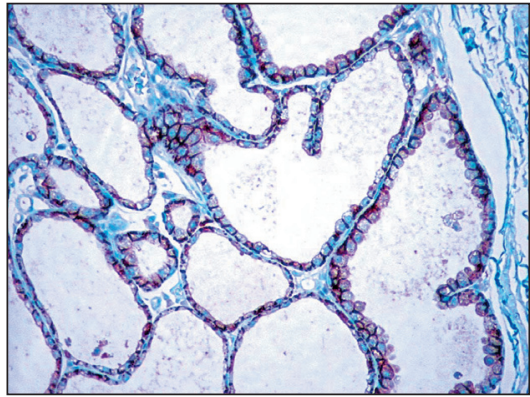

Fig. 1a. Apocrine gland as internal positive control of claudin-7. IHC.

Magnification $\times 100$

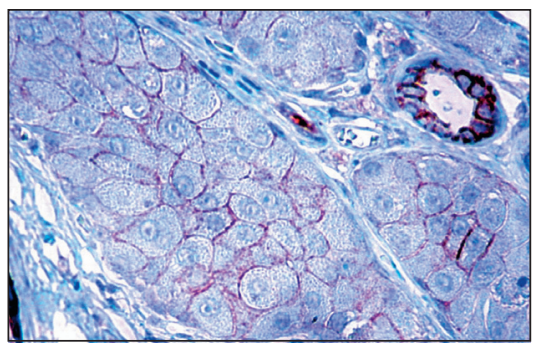

Fig. 2. Membrane-bound expression of claudin-7 molecule in an intact canine hepatoid gland. At the right side of the picture the apocrine gland (internal positive control) can be seen. IHC. Magnification $\times 400$
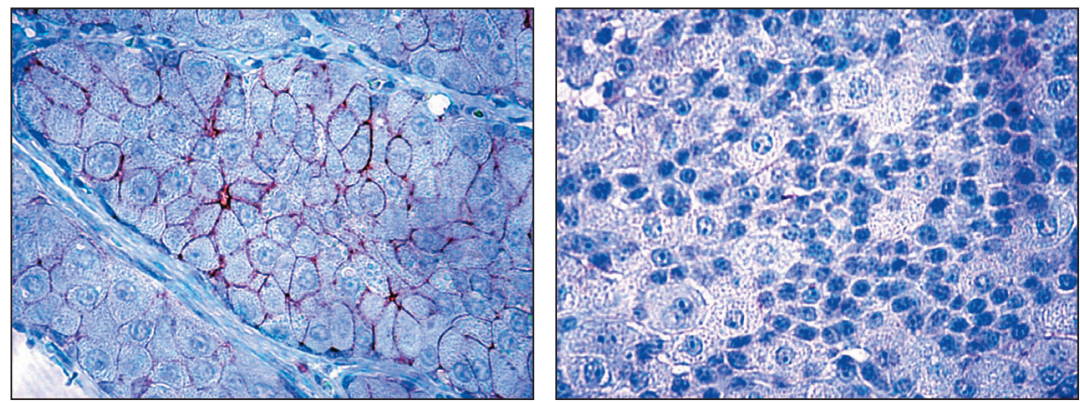

Fig. 4. Intense membrane expression of Fig. 5. Loss of claudin-7 expression in claudin-7 in adenoma of the canine hepatoid epithelioma of the canine hepatoid gland. IHC. gland. IHC. Magnification $\times 400$

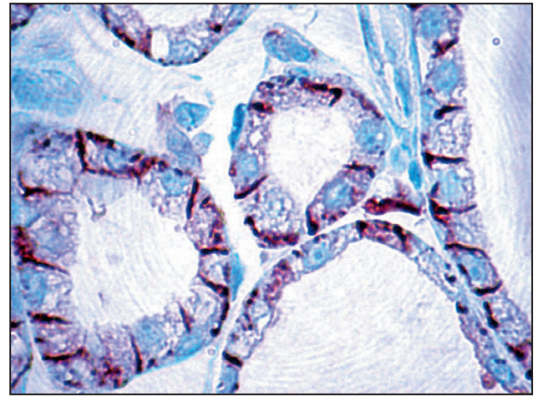

. 1b. Higher magnification. IHC.

Magnification $\times 400$

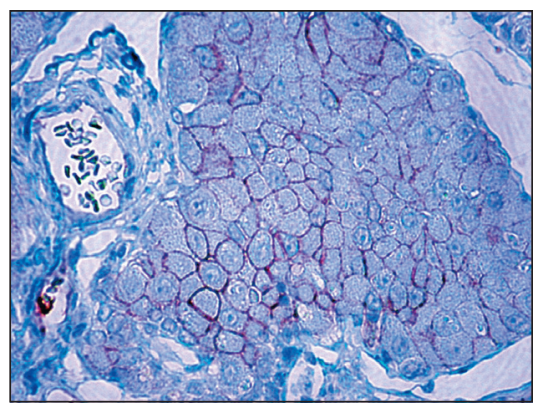

Fig. 3. Expression of claudin-7 in a nodular hyperplasia of canine hepatoid gland. IHC. Magnification $\times 200$ 


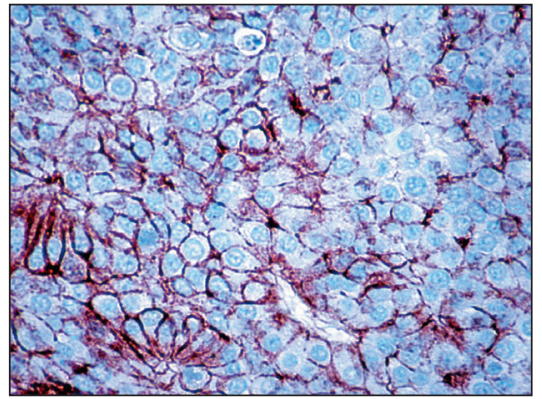

Fig. 6. Intense expression of claudin-7 in a welldifferentiated carcinoma of the canine hepatoid gland. Some tumour cells showed cytoplasmic immunoreactivity for claudin-7 molecule. IHC. Magnification $\times 200$

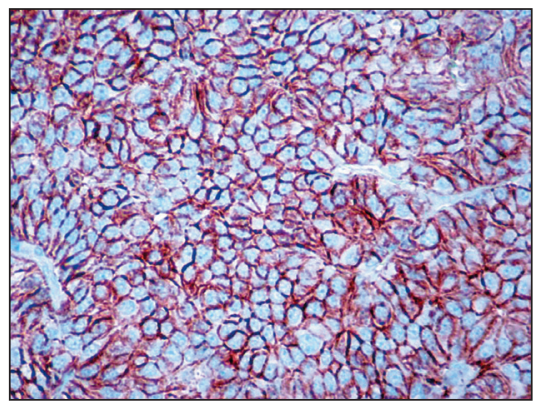

Fig. 8. Overexpression of claudin-7 in a poorly differentiated carcinoma of the canine hepatoid gland. Some neoplastic cells showed cytoplasmic immunoreactivity for claudin-7 molecule. IHC. Magnification $\times 100$.

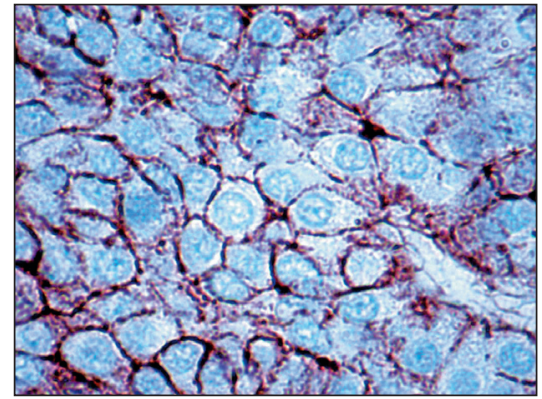

Fig. 7. Higher magnification of a welldifferentiated carcinoma of the canine hepatoid gland. IHC. Magnification $\times 400$

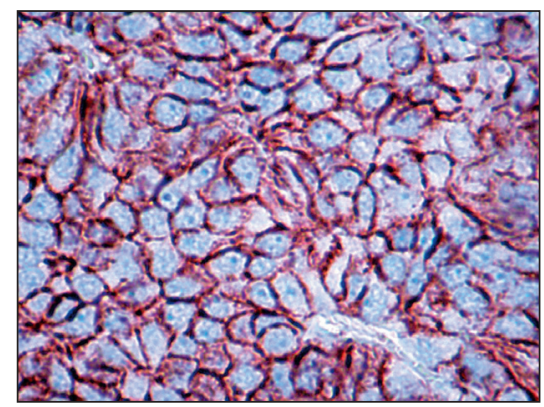

Fig. 9. Similar picture at higher magnification. IHC. Magnification $\times 200$ 